Fixed Point Theory, 21(2020), No. 1, 305-308

DOI: $10.24193 /$ fpt-ro.2020.1.21

http://www.math.ubbcluj.ro/ nodeacj/sfptcj.html

\title{
SOME FIXED POINT RESULTS ARE FUTILE FOR THE METRIC SPACES WITH FINITE DIAMETER
}

\author{
EHSAN POURHADI
}

International Center for Mathematical Modelling in Physics and Cognitive Sciences, Linnaeus University, SE-351 95, Växjö, Sweden and Department of Mathematics, Iran University of Science and Technology, Narmak, Tehran 16846-13114, Iran

E-mail: epourhadi@alumni.iust.ac.ir

\begin{abstract}
In this short note, we state some crucial facts which have to be accompanied in a series of results in the literature. Furthermore, the aim of this paper is to warn researchers to be cautious in modeling different problems governed by expansive or contractive type mappings, in the setting of a bounded metric space.
\end{abstract}

Key Words and Phrases: Expansive mapping, contractive mapping, partial ordering.

2010 Mathematics Subject Classification: 47H09, 47H10, 54H25.

Acknowledgment. The author would like to express his sincere gratitude to the anonymous referees for the useful comments.

\section{REFERENCES}

[1] J. Garcia Falset, O. Mleşnitę, Coincidence problems for generalized contractions, Appl. Anal. Discrete Math., 8(2014), 1-15.

[2] J.R. Graef, J. Henderson, A. Ouahab, Some Krasnosel'skii type random fixed point theorems, J. Nonlinear Funct. Anal., 2017(2017), Art. ID 46, 1-34.

[3] Y. Han, S. Xu, Some new theorems of expanding mappings without continuity in cone metric spaces, Fixed Point Theory Appl., 2013(2013), no. 3.

[4] X. Huang, C. Zhu, X. Wen, Fixed point theorems for expanding mappings in cone metric spaces, Math. Rep., 14(2012), no. 2, 141-148.

[5] A. Ouahab, Some perov's and krasnosel'skii type fixed point results and application, Commun. Appl. Anal., 19(2015), 623-642.

[6] W. Shatanawi, F. Awawdeh, Some fixed and coincidence point theorems for expansive maps in cone metric spaces, Fixed Point Theory Appl., 2012, 19(2012).

[7] M.-A. Taoudi, T. Xiang, Weakly noncompact fixed point results of the Schauder and the Krasnoselskii type, Mediterr. J. Math., 11(2014), 667-685, https://doi.org/10.1007/s00009-013-0304y.

[8] S.Z. Wang, B.Y. Li, Z.M. Gao, Some fixed point theorems on expansion mappings, Adv. Math. (China), 11(1982), no. 2, 149-153.

[9] S.Z. Wang, B.Y. Li, Z.M. Gao, K.K. Iséki, Some fixed point theorems on expansion mappings, Math. Japonica, 29(1984), 631-636. 
[10] F. Wang, F. Wang, Krasnosel'skii type fixed point theorem for non-linear expansion, Fixed Point Theory, 13(2012), no. 1, 285-291.

[11] T. Xiang, R. Yuan, A class of expansive-type Krasnosel'skii fixed point theorems, Nonlinear Anal., 71(2009), 3229-3239.

Received: February 14, 2018; Accepted: April 4, 2018. 